\title{
Elementary Science Classroom Learning with Wireless Response Devices - Implementing Active and Experiential Learning
}

\author{
Yu-Fen Chen ${ }^{* 1}$, Chen-Chung Liu ${ }^{* 2}$, Ming- Hung Yu ${ }^{* 3}$, Sung-Bin Chang ${ }^{* 1}$, Yun-Chen Lu ${ }^{* 4}$ \\ , Tak-Wai Chan ${ }^{* 2}$ \\ ${ }^{* 1}$ Dept. of Computer Science Information Engineering \\ ${ }^{*}$ Graduate Institute of Network Learning Technology \\ National Central University, Taiwan \\ ${ }^{*}$ \{amychen, legend\}@cl.ncu.edu.tw \\ ${ }^{*}\{$ ccliu, chan\}@lst.ncu.edu.tw \\ ${ }^{* 3}$ Degree Program of E-Learning, \\ College of Science \\ National Chiao Tung University, Taiwan \\ mh.yue@msa.hinet.net \\ ${ }^{* 4}$ Chu-Wei Elementary School, Taiwan \\ swaro@mail.jwes.tyc.edu.tw
}

\begin{abstract}
Active learning enables learners to actively engage in learning. Learning not only transfers material to students for learning, but also encourages greater mental engagement and more extensive studentstudent and student-instructor interaction than does a typical lecture class. Peer Instruction (PI) engages students in active learning by achieving continuous instructor-student interaction in a physics lecture. However, the methodologies and the effectiveness of implementing PI for elementary school students have seldom been clarified. This study explores the possibility of adopting PI in an elementary science classroom. The research considerations of the study are as follows: (1) how wireless technology can enhance PI in elementary science classroom; (2) how a teacher can engage students in pre-class reading, and (3) whether elementary school students have sufficient social skills to perform a PI discussion? These questions are examined by observing how the PI pedagogical model worked with a wireless response system in elementary science classroom. Based on the observation, this study also proposes a way of improving the PI learning experience of elementary school students by adding experiments and observations during peer discussion to explain concepts and phenomena in physics.
\end{abstract}

\section{Introduction}

Many investigations confer that learning gains in introductory university physics courses may be increased by " active-learning" instructional methods
[9][10][12]. Active learning is a process whereby learners are actively engaged in the learning process. Learning not only means transmitting material to be learned to students, but also increasing mental engagement and student-student and studentinstructor interaction, than is found in a typical lecture class.

Students in active learning are much more actively engaged in their own learning while educators take a more guiding role than in conventional instruction. Therefore, educators have to create opportunities for students involved in active learning. Educators and researchers have developed various pedagogical models to enhance active learning in universities [11]. Peer Instruction (PI) [9] allows students to actively learn via continuous instructor-student interaction for a physics lecture. PI exploits student interaction in class and attracts students' attention on learning concepts. The PI process involves ConcepTests activities where teachers probe conceptual conflict among students with conceptual multiple-choice questions. Concept learning then occurs when students attempt to convince their neighbors of their own answers. Through the peer discussion, PI facilitates students to build knowledge actively, not only in university general physics courses, but also in other courses, including general chemistry, medical physiology, astronomy, calculus and general biology.

However, few studies have been performed to clarify the methodologies and effectiveness of implementing PI for elementary school students. This study explores the possibility of adopting PI in elementary science classroom. PI is a pedagogical model that can be implemented without any 
technological support. However, the teacher must diligently strive to arrange ConcepTest questions, compare student answers and mediate peer discussion. Additionally, university students have adequate social skills, such as the ability to exemplify concepts and to argue with contradiction to conduct effective perspective exchange. However, whether elementary school students have sufficient social skills to perform effective PI activity is not clear. Therefore, the research questions of this study are:

(1) How can wireless technology enhance PI in elementary science classrooms?

(2) How does a teacher engage students in pre-class reading?

(3) Do elementary school students have sufficient social skills to perform PI discussion?

This study elaborates assumptions on these questions, and these assumptions are examined by observing how the PI pedagogical model works with a wireless response system in an elementary science classroom. Based on the observation, this study also proposes a model to improve the PI learning experience of elementary school students by adding experiments and observations during peer discussion to elucidate concepts and phenomena in physics.

\section{Wireless response devices}

Although using technology to support education is a current trend, the applicability of applied technology must be evaluated carefully. Many studies have discussed how students can work with computing devices, such as PDAs, notebooks, tablet PCs and smart phones, to improve learning. However, Roschelle claims that 'pedagogical applications' are often led down the wrong road by complex views of technology and simplistic views of social practices. Further research is needed that tells the story of rich pedagogical practice arising out of simple wireless and mobile technologies [13]." Since this study attempts to investigate how technology can be utilized to augment PI learning activity, a simple, easy-use, well-controlled system is needed rather than sophisticated wireless devices. Therefore, this study adopts a wireless response system to facilitate student-instructor communication. The wireless response system, named EduClick [3], is a technology-enabled learning environment for improving learning interactivity by transferring, collecting, processing and displaying students' responses in an ordinary classroom. Several similar systems, such as Classtalk [2] and the Personal Response System (PRS) [1], currently exist. The general hardware and software of newest EduClickII
[7] are described as follows.

EduClickII hardware (Figure 5): The EduClickII hardware includes two devices, a set of wireless response devices and the response signal receiver. EduClickII operates by existing classroom facilities, i.e. a teacher's laptop computer, a projector and a large display. The wireless response device is a straightforward and convenient personal handheld device with no computing power but with remote communication capability. Every student in the classroom can utilize this device to respond immediately to the teacher's questions. The response signal receiver receives the signals sent from all wireless response devices, and transfers these data to the teacher's laptop for further processing. The wireless response device and receiver are infrared. The teacher's laptop, which is linked to the receiver and the large display, has sufficient computing power to process the response data transferred from the receiver and display the result of student responses on a large screen [7].

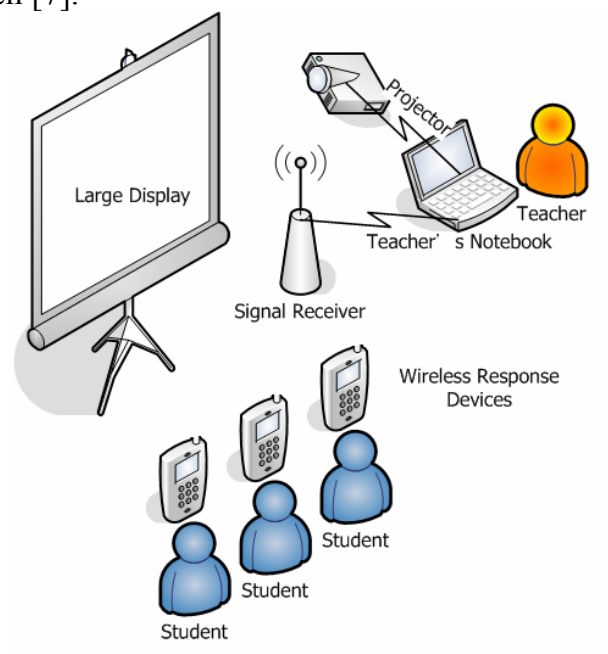

Figure 1. The configuration of the EduClickll.

EduClickII software: The software has five primary functions: (1) supporting content preparation (i.e. authoring materials); (2) displaying content (i.e. depicting materials on the screen); (3) gathering all responses and transforming them into meaningful data (i.e. grading students' answers); (4) storing and retrieving transformed data, and (5) creating reports [7].

Wireless response systems can smooth the flow of the PI pedagogical model (Figure 2), giving each student an opportunity to participate anonymously in the activity in a class. Each student can realize the status of the entire class immediately, and compare it with his own status without exposing it to the whole class. When students input data by signal transmitters, 
the system gathers the inputs and processes them simultaneously using almost-parallel processing. This task is performed more efficiently than it would be by a human. EduClickII is an effective tool for decreasing the amount of time spent by teachers and their workload associated with such tasks. EduClickII can immediately collect and process all students' responses, helping teachers understand the learning status or each student, and helping them make decisions instantly during class [8]. The teacher and students can utilize these functions to engage in interactive learning activities.

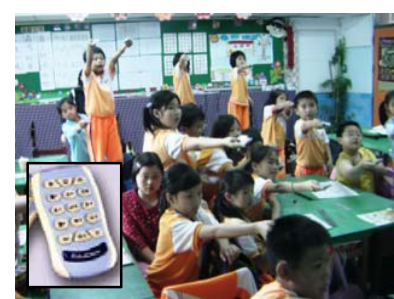

(a) Using wireless response devices

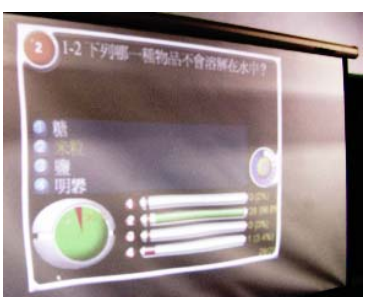

(b) Displaying results of students' responses

\section{Figure 2. The situation of using the EduClickll}

However, the EduClickII software needs a minor modification to support PI well. The EduClickII software displays the correct rate of whole class's answer, the amount of each option which a student selected for a question, and the correct answer simultaneously. However, in the PI pedagogical model, the teacher and students should only see the correct rate without the correct answer and the amount of each option, since these might imply which one is the correct answer before students discuss to obtain the correct answer. This study uses other software to hide these unnecessary information mentioned above, the functions of EduClickII will be recoded shortly to support the PI pedagogical model.

\section{Engaging elementary school students in pre-class reading}

The pre-class reading activity of PI entails encouraging students in individual thinking. Using the Mazur PI pedagogy model, undergraduate students can read assigned materials and compose individual answers to reading quizzes since they can prepare themselves before class.

However, interviews with two elementary school teachers show that elementary school teachers in Taiwan believe that elementary school students cannot prepare themselves before class. Students might turn to their parents to ask for their help, since the parents consider the reading quizzes as assigned homework, and therefore help their children to perform the reading quiz. Consequently, teachers in Taiwan cannot easily inspire students to think independent and discover the answer individually through the reading quiz.

To prevent such a situation from occurring, a library exploration activity was designed to bring kids to perform pre-class reading activity in the library. Students were asked to participate in the pre-class reading activity at school in the morning, one day before the science class. The teacher gave each student a working sheet with a reading quiz, and then asked them to read the quiz and to try answering the questions in 20-30 minutes. The teacher then brought the students to the school library and allowed students to discover the correct answers by searching the Internet, their textbooks or library books. The students were then asked to hand in the worksheets to the teacher before leaving school for the day.

During the activity, instead of lecturing the class, the teacher plays a guiding role to help students figure out the meaning of the quizzes, deliberate the answers of the quizzes, reflect their own prior knowledge relating to these quizzes and search for relevant data and information to solve the quizzes by themselves. In other words, the activity is designed to achieve the goal of pre-class reading by asking students to answer reading quizzes. Since pre-class reading has no definite boundary, pre-class reading is one category of independent learning, in which the learner can make the necessary decisions to meet the learner's own learning needs [5]. Pre-class reading enables students to become capable, self-reliant, self-motivated lifelong learners.

\section{PI discussion activity with experiential demonstration}

In the PI pedagogical model, students have discuss with others about their answer for ConcepTest. Cognitive conflict arises when students have different answers. An individual experiences conceptual conflict when engaged in controversy as his position is challenged by contradictory ideas and arguments. Conflict resolution may lead to high-quality learning and decision-making processes [4]. In the PI pedagogical model, when convincing their peers, students must also listen to their peers to explore, extend, clarify and reflect on their thoughts, ideas, feelings and experiences. Students who encounter others with points of view different from his own must defend or support their own opinions with convincing evidence. 
However, elementary school students do not always behave properly in PI discussion activities, and cannot always provide supportive evidence when trying to convincing their peers of their opinions. Students can not positively learn only from discussion. This study also videotaped students' dialogue during their discussion. Table 1 and Table 2 list student dialogues regarding the question: " There are different temperatures and humidity levels in these four cities, $\mathrm{A}$ $\left(25^{\circ} \mathrm{C}, 80 \%\right), \mathrm{B}\left(30^{\circ} \mathrm{C}, 10 \%\right), \mathrm{C}\left(40^{\circ} \mathrm{C}, 10 \%\right)$ and $\mathrm{D}(32$ ${ }^{\circ} \mathrm{C}, 75 \%$ ). Which is the most uncomfortable city in which people feel hot and damp?" The correct answer is D, and the students with IDs 20 and 2 initially selected the correct answer. When students discussed the question with others, they did not know whose answer was right. Table 1 reveals that Student 20 successfully persuaded Student 14 , but did not persuade Student 1. Although Student 20 answered the question correctly, the others did not follow his answer since he did not provide strong convincing reasons to support his position. Considering students' academic achievement (Table 3), the analytical results show that S1 still firmly believed his own choice, although S20, whose academic achievement is higher than $\mathrm{S} 1$, had a different choice. Dialogues frequently occurred between students in this study.

\section{Table 1. Group 1's dialogues about} temperature and humidity

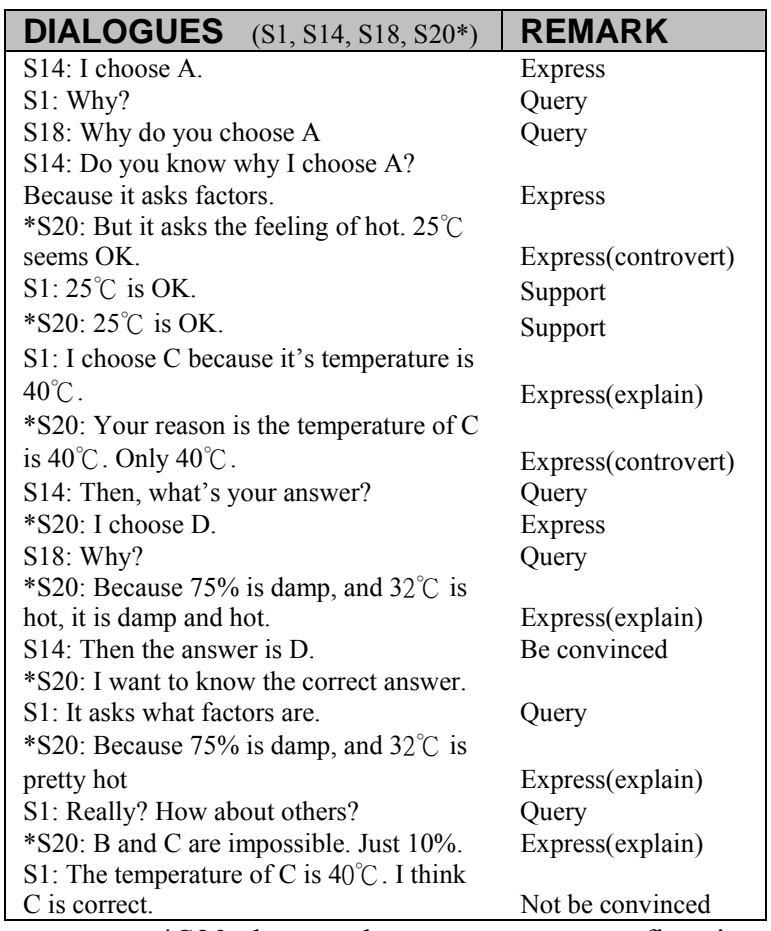

*S20 chooses the correct answer at first time.
Table 2 shows that Student 2 did not express his position. Student 2 was the only student who answered correctly the first time in this group. By contrast, Student 17 expressed his opinion persistently although he incorrectly believed the temperature is the only factor causing people to feel damp. Considering students' personality (Table 3 ), student 5 is sensitive and lacking confidence, but he expressed his opinion by giving an example. Students 17, 2, and 8 are active, spry and studious, and all expressed profusely at the discussion activity. In particularly, Student 17 is very curios about what he does not know. However, Student 2 did not express himself much in this dialogue since he was less confident in his answer to the question. Therefore, he kept silence and let student 17 talked.

\section{Table 2. Group 4's dialogues about temperature and humidity}

\begin{tabular}{|l|l|}
\hline DIALOGUES (S2*, S5, S8, S17) & REMARK \\
\hline S17: I choose C. & Express \\
S5: I choose C, too. & Support \\
S17: The temperature of A and B is low. & \\
$40^{\circ} \mathrm{C}$ is high, it depends on sweat, and it is & \\
hot & Express(explain) \\
S8: And depends on humidity. & Express \\
S5: It's hot and damp. Sweating with lots & \\
of oil. We get sweating easily when the & Express(give a \\
temperature is high. & example) \\
S17: Any one choose A? & Query \\
S5: I choose C, because it's hotter and we & \\
sweat a lot. & Express(explain) \\
*S2: I choose D. & Express \\
S17: Explain it. & \\
S5: I am done. & \\
S17: A and B, I choose the one with high & \\
temperature. It is hotter when the & \\
temperature is high. & Express(explain) \\
\hline
\end{tabular}

*S2 chooses the correct answer at first time.

The analytical results indicate that these students have fewer academic references in which students refer other's academic achievement in the school of each other when they express themselves. The students can better concentrate on figuring out the correct answer, rather than following a superior without reasons.

Students discussing without academic references is a good result. However, students cannot easily focus their opinions since they lack supporting evidence and good expression. Students can be taught the correct concept by many approaches. However, to avoid intervening in students' knowledge construction in the discussion activity, an experiment operated by the teacher was designed and demonstrated in front of the students. 
Table 3. Personality of sample students

\begin{tabular}{cccccc}
\hline \multicolumn{5}{c}{ Student } \\
\hline ID & Rank $^{*}$ & \multicolumn{4}{c}{ Personality } \\
\cline { 3 - 5 } & & Active & Warm- \\
hearted & Spry & Studious \\
\hline S1 & $9^{\text {th }}-11^{\text {th }}$ & $\star \star$ & $\star \star \star$ & $\star \star \star$ & $\star \star \star$ \\
S14 & $9^{\text {th }}-11^{\text {th }}$ & $\star \star$ & $\star$ & $\star \star$ & $\star \star$ \\
S18 & $9^{\text {th }}-11^{\text {th }}$ & $\star \star$ & $\star$ & $\star$ & $\star \star$ \\
S20 & $5^{\text {th }}$ & $\star$ & $\star$ & $\star$ & $\star \star \star$ \\
\hline S2 & $15^{\text {th }}$ & $\star \star \star$ & $\star \star$ & $\star \star \star$ & $\star \star$ \\
S5 & $22^{\text {nd }}$ & $\star$ & $\star$ & $\star$ & $\star$ \\
S8 & $7^{\text {th }}-8^{\text {th }}$ & $\star \star$ & $\star \star$ & $\star \star \star$ & $\star \star$ \\
S17 & $12^{\text {th }}$ & $\star \star \star$ & $\star \star$ & $\star \star \star$ & $\star \star \star$ \\
\hline
\end{tabular}

* Rank of students' academic achievement

Students in an elementary science course need to form their ideas through observing nature, experiments or videos [6]. After demonstrating an experiment, the teacher can ask students to discuss what phenomena they observe (Figure 3). Students may construct their knowledge more concretely by expressing their experience with others. Additionally, the demonstrated experiment can stand as evidence or examples for students to focus their discussion.

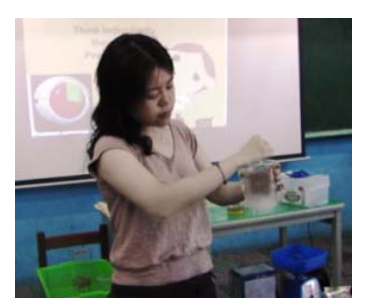

(a) Demonstrating an experiment

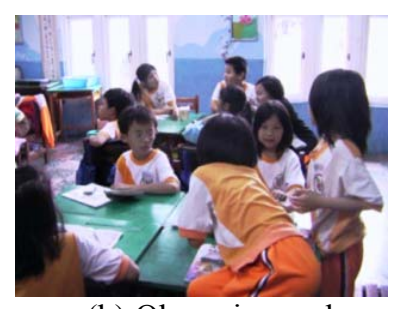

(b) Observing and discussing
Figure 3. The teacher demonstates an experiment for students to observe \& discuss

\section{Active and experiential learning pedagogical model with wireless response devices}

This study proposes an active and experiential learning pedagogical model with EduClickII including the improvements mentioned above. The proposed model is described as follows.

The teacher has to prepare instructional materials, such like reading-quizzes, ConcepTests and demonstrated experiments or videos before teaching a class. Reading quizzes of one unit contain 3 to 5 openend questions, which are designed to draw forth some life experience of students, to stimulate them to think about topics in a new unit.

For example, "Have you watched a weather forecast on TV? What does a weather forecast tell us?" "Have you seen clouds in sky? Try to observe them now. What do they look like? What is the weather when you observe it?" "What cause the weather to change?" The teacher also can design a small-scale hands-on experiment within a reading quiz. E.g. "Take 2 toilet papers, roll one up tightly, and put both toilet papers into the water surface at the same time. Which paper absorbs water faster?" Each unit typically consists of four to eight concepts. The pedagogical model requires two multiple-choice questions for each concept. The teacher has to prepare $8-16$ ConcepTest questions for one unit, such as "Four cities have different temperatures and humidity levels, A $\left(25^{\circ} \mathrm{C}, 80 \%\right)$, B $\left(30^{\circ} \mathrm{C}, 10 \%\right), \mathrm{C}\left(40^{\circ} \mathrm{C}, 10 \%\right)$ and $\mathrm{D}\left(32^{\circ} \mathrm{C}, 75 \%\right)$ city. Which is the most comfortable city?" "After putting 30 grams Alum, 30 grams salt, 30 grams rice, and 30 grams iron filings separately into 4 glasses of 100 grams water, and filtering out unmelted materials, which glass of water is the heaviest?"

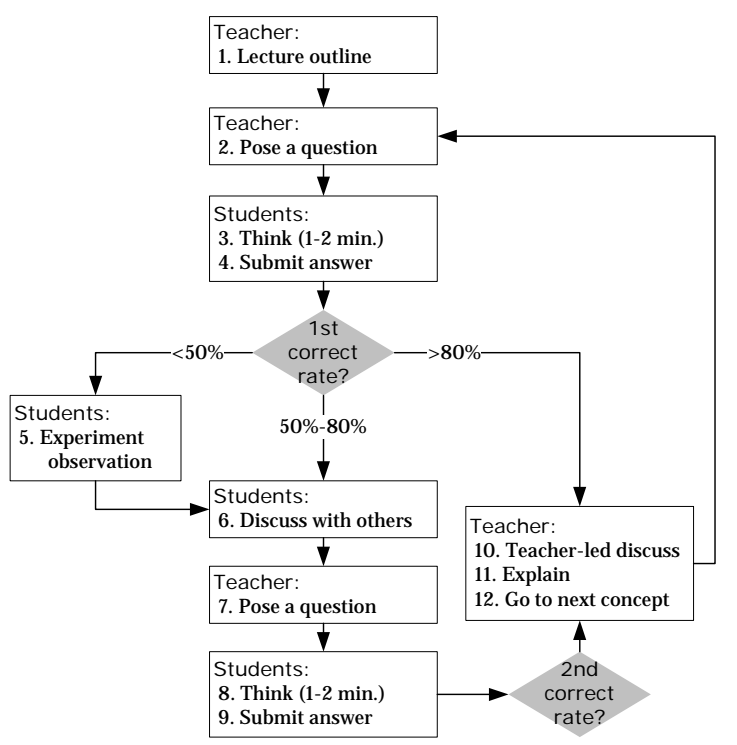

Figure 4. Flowchart of active and experiential learning pedagogical model

The active and experiential learning pedagogical model has two phases. The first phase is to ask students to perform pre-class reading and answer reading-quizzes before starting a new curriculum unit. The second phase is illustrated with a flowchart (Figure 4) as follows. 
In the class, the teacher begins with lecturing outline and introducing a summary of students' reading quizzes within 10 minutes. The teacher then poses a ConcepTest question to students. Students think for one to two minutes without discussing, and then submit their answers using wireless response devices within 30 seconds. The large display screen illustrates the status of each student's answer. The green color of a round icon with student's ID signifies that the student has not yet answered. The red color signifies that the student has submitted an answer. A flickering icon signifies that the student has changed his answer. The teacher can determine whether to extend the thinking time or not depending on the answer speed of students. Once all students have submitted their answers, the teacher displays the correct rate on screen immediately. If the first correct rate is less than $50 \%$, then the teacher demonstrates an experiment or plays a video for students to observe, and then the students discuss it during a period of 1 to 2 minutes. Students then answer another ConcepTest question concerning the same concept. After all students have submitted their answers, the teacher can explain the concept briefly if the second correct rate is high. If the second correct rate remains low, then the teacher can discuss with students, identify students' problems by asking them why the selected the other options, and then elaborates the correct answer slowly before proceeding with the next concept. If the first correct rate is between $50 \%$ and $80 \%$, then the teacher omits the experiment and lets students discuss directly with others. If the first correct rate is larger than $80 \%$, then the teacher omits the experiment and students' discussion, directly corrects the misunderstandings of the minority, gives a brief direct explanation of the correct answer and then proceeds with the next concept.

\section{Evaluation of the active and experiential learning pedagogical model with wireless response devices}

This evaluation involves quantitative and qualitative analysis on learning effects based active and experiential learning pedagogical models with wireless response devices.

The subjects were 59 students at an elementary school located in a suburb. Two Grade 3 (9-10 years old) classes, consisting of 29 and 30 students who had never used EduClick in real classroom activities, and one elementary school science teacher, participate in the evaluation.

In the quantitative analysis, this study adopted a nonequivalent pretest-posttest control group experimental design. The class of 29 students was the experimental group, and the class of 30 students was the control group. This experimental design involved two tests - one for pre-testing, focusing on the status of students' prior knowledge, and another for posttesting, focusing on the learning effect of students' achievements. The mean score of the experimental group in the pre-test was $60.5(\mathrm{SD}=13.11)$, and the mean score of the control group was $58.3(\mathrm{SD}=12.82)$. The t-test analysis reveals insignificant differences between the experimental and control groups $(\mathrm{t}=0.65$, $\mathrm{p}=0.52$ ). The above statistical results show that the experimental and control groups had similar prior knowledge levels.

The quantitative analysis included three phases. In the first phase, the participants answered the pre-test questions. In the second phase, the experimental group utilized EduClickII to learn seven units of the science curriculum in real classroom situations for six weeks with ten periods, while the control group was lectured in the conventional style by the same teacher as the experimental group. In the third phase, the participants answered the post-test questions. Each pre-test and post-test contained 20 multiple-choice questions (5 points for each item), and the perfect score was 100 points. The students answered these questions within 25 minutes.

For the qualitative analysis, the teacher was interviewed with structured questions, and quasistatistics were applied to analyze the students' responses during the discussion.

\subsection{Results of quantitative analysis}

All the participants took both the pre- and the posttests and provide complete answers, so the final statistical analysis relied on the data obtained from the 59 students. The data were analyzed using the t-test method. The results of the quantitative analysis are presented as follows.

6.1.1. Does the active and experiential learning pedagogical model with wireless response devices improve the learning effect of the students' achievements? The mean score of the experimental group in the pre-test was $60.5(\mathrm{SD}=13.11)$. In the posttest, the mean score of the experimental group was 83.6 ( $\mathrm{SD}=11.17)$. According to Table 4, the t-test analysis reveals significant differences between the pre-test and post-test $(\mathrm{t}=-9.90, \mathrm{p}<0.001)$. The above statistic results demonstrate that the active and experiential learning pedagogical model with wireless response devices can significantly raise students' achievements. 
Table 4. The paired samples test results of experimental group's score

\begin{tabular}{|c|c|c|c|c|c|}
\hline $\begin{array}{c}(\mathrm{N}=29) \\
(\mathrm{p}<.001)\end{array}$ & Test & Mean & $\begin{array}{c}\text { Std. } \\
\text { Deviation }\end{array}$ & $\mathrm{t}$ & $\mathrm{p}$ \\
\hline \multirow{2}{*}{$\begin{array}{l}\text { Experimental } \\
\text { Group's Score }\end{array}$} & Pre-test & 60.5 & 13.11 & \multirow{2}{*}{-9.90} & \multirow{2}{*}{0.000} \\
\hline & Post-test & 83.6 & 11.17 & & \\
\hline
\end{tabular}

6.1.2. Is the active and experiential learning pedagogical model with wireless response devices more effective than lecture pedagogical model? The mean score of experimental group in the post-test was 83.6 $(\mathrm{SD}=11.17)$, and the mean score of the control group was $76.2(\mathrm{SD}=16.54)$. According to Table 5, the t-test analysis reveals significant differences between the experimental and control groups $(\mathrm{t}=2.03, \mathrm{p}<0.05)$. The above statistic results confirm that the active and

Table 5. The independent samples test results of two group's post-test score

\begin{tabular}{ccccccc}
\hline \multirow{2}{*}{ Group } & \multicolumn{2}{c}{ Pre-Test Score } & \multicolumn{2}{c}{ Post-Test Score } & $(\mathrm{p}<.05)$ \\
\cline { 2 - 6 } & Mean & $\begin{array}{c}\text { Std. } \\
\text { Deviation }\end{array}$ & Mean & $\begin{array}{c}\text { Std. } \\
\text { Deviation }\end{array}$ & $\mathrm{t}$ & $\mathrm{p}$ \\
\hline Experimental group & 60.5 & 13.11 & 83.6 & 11.17 & 2.03 & 0.047 \\
\hline Control group & 58.3 & 12.82 & 76.2 & 16.54 & \\
\hline
\end{tabular}

\subsection{Result of qualitative analysis:}

In addition to the above quantitative results, the factors improving learning effect among the students was also investigated. The teacher was interviewed, and quasi-statistics were applied to analyze the students' responses in the discussion process. After arranging and analyzing the interview records and students' response logs, the following results were obtained.

6.2.1. The teacher's viewpoint. The teacher's opinions are quoted as follows to stand for the advantages of the active and learning pedagogical model.

"I regard reading-quizzes as guiding assignments, no matter whether students' answers are right or wrong, students do think more extensively."

"Now, students are more active in class. They have better learning attitudes. Since I changed my instructional style, they have had to pay more attention in class. And I have started controlling the instruction process more clearly, and can explicitly tell students what I expect them to do."

"This pedagogical model with EduClickII lets teacher, students and materials interact more smoothly and effectively." experiential learning pedagogical model is more effective than the lecture pedagogical model.

Table 5 also shows that the std. deviation of the experimental group is lower in the post-test than in the pre-test; conversely, the std. deviation of control group is higher in the post-test than in the pre-test. This finding confirms that the model with wireless response devices can promote achievement of each student in the class - not only superior students, but also inferior students. No one is left behind.

“After discussion, students can propose more specific questions; Therefore, I can realize their problems and have to elaborate more carefully."

"I find that some students go home and tell their parents about class. Parents tell me this seldom happen before. I am glad that students want to share their experience with parents."

"It does cost more time to prepare course, but I would like to use this pedagogical model in another three classes that I teach. I believe that I can do it more efficiently next time."

"I think this pedagogical model has a strong chance in mathematics, language and sociology courses, but the teacher should have enough ability to help students focus their discussion."

6.2.2. The analysis of students' responses. This study sampled 35 out of 56 concepts which are taught during the six weeks of the experiment. Students answered the questions of these 35 concepts twice. Figure 5 displays their frequently of answering correctly. The square indicates that the teacher demonstrated the experiment after the students' first answer. The circle indicates that the teacher omitted the experiment. In both situations, all students discussed with others before answering again. 


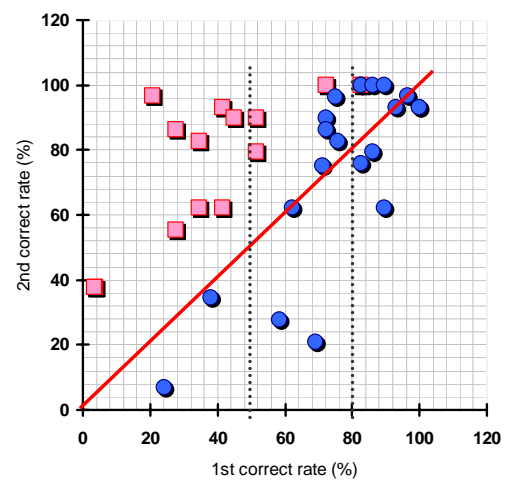

Figure 5. $1^{\text {st }}$ and $2^{\text {nd }}$ correct rate of whole class

Figure 5 demonstrates that students can always learn from observing and discussing experiments, but can not learn positively from only discussing with others.

\section{Conclusion}

This study presents a practical application of wireless technologies for education, and explores the following three research questions:

(1) How can wireless technology improve PI in elementary science classrooms?

(2) How does a teacher engage students in pre-class reading?

(3) Do elementary school students have sufficient social skills to perform PI discussion? After observing how the PI pedagogical model worked with a wireless response system in an elementary science classroom, this study proposes the active and experiential learning pedagogical model which improves the PI learning experience of elementary school students by adding experiment and observation during peer discussion to explain the concepts and phenomena in physics.

Silberman states that active learning is effective for the following reasons: "What I hear, I forget. What I hear and see, I remember a little. What I hear, see and ask questions about or discuss with someone else I begin to understand. What I hear, see, discuss, and do, I acquire knowledge and skill. What I teach to another, I master [14]." The evaluation results with 59 thirdgrade elementary school students from this study support this active-learning credo. Students' performance on tests increases when they discuss concepts, observe phenomena, and teach classmates by convincing them.

Specifically, the qualitative analysis of students' dialogues shows that many elementary school students lack of social skills to reason successfully, hence, PI pedagogical model can not be adopted in elementary schools without modification. In other words, "What I hear, see, and ask questions about or discuss with someone else I begin to understand. But, I am not always right."

Finally, the qualitative analysis of the participant teacher's opinions indicates that the active and experiential learning pedagogical model with the wireless response system (EduClickII) raises instructional quality significantly, but not increases the cost substantially.

\section{References}

[1] Cue, N. (1998). A Universal Learning Tool for Classrooms? Proceedings of the First Quality in Teaching and Learning Conference, 1998.

[2] Dufresne, R.J., Gerace, W.J., Leonard, W.J., Mestre, J.P., \& Wenk, L. (1996). Classtalk: a classroom communication system for active learning. Journal of Computing in Higher Education, 7, 3-47.

[3] Huang, C.W., Liang, J.K., \& Wang, H.Y. (2001). EduClick: A Computer-Supported Formative Evaluation System with Wireless Devices in Ordinary Classroom. Proceedings of International Conference on Computers in Education (ICCE), 2001, 1462-1469.

[4] Johnson, D.W., Johnson, R.T. (1995). Teaching students to be peacemakers, Edina, MN, Interaction Book Company.

[5] Kesten, C. (1987). Independent Learning. Regina: Saskatchewan Education.

[6] Kolb, D.A. (1984). Experiential learning: experience as the source of learning and development. Prentice Hall, New Jersey.

[7] Liu, T.C., Liang, J.K., Wang, H.Y., \& Chan, T.W. (2003). The Features and Potential of Interactive Response System. Proceedings of International Conference on Computers in Education (ICCE), 2003, 315-322.

[8] Liu, T.C., Liang, J.K., Wang, H.Y., Chan, T.W., \& Wei, L.H. (2003). Embedding EduClick in Classroom to Enhance Interaction. Proceedings of International Conference on Computers in Education (ICCE), 2003, 117-125.

[9] Mazur, E. (1997). Peer Instruction: a User's Manual. Prentice Hall, New Jersey.

[10] Meltzer, D.E., Manivannan, K. (2002). Transforming the lecture-hall environment: The fully interactive physics lecture. American Journal of Physics, 70(6), 639-654.

[11] Michael, J.A., Modell, H.I. (2003). Active Learning in Secondary and College Science Classrooms: A Working Model for Helping the Learner to Learn. Mahwah, NJ: Lawrence Erlbaum Associates.

[12] Novak, G., Gavrin, a., Christian, W., \& Patterson, E. (1999). Just-In-Time Teaching: Blending Active Learning with Web Technology. Prentice Hall.

[13] Roschelle, J. (2003). "Unlocking the learning value of wireless mobile devices." Journal of Computer Assisted Learning, 19(3), 260-272. 
[14] Silberman, M. (1996). Active Learning: 101 Strategies to Teach Any Subject. Boston: Allyn\& Bacon. 